\title{
问

$10-2015$

\section{Photocatalytic Concrete Pavements: Laboratory Investigation of NO Oxidation Rate Under Varied Environmental Conditions}

Joel K. Sikkema

Dordt College, joel.sikkema@dordt.edu

Sae-Kee Ong

lowa State University

James E. Alleman

lowa State University

Follow this and additional works at: https://digitalcollections.dordt.edu/faculty_work

Part of the Construction Engineering and Management Commons

\section{Recommended Citation}

Sikkema, J. K., Ong, S., \& Alleman, J. E. (2015). Photocatalytic Concrete Pavements: Laboratory Investigation of NO Oxidation Rate Under Varied Environmental Conditions. Construction and Building Materials, 100, 305. https://doi.org/10.1016/j.conbuildmat.2015.10.005

This Article is brought to you for free and open access by Dordt Digital Collections. It has been accepted for inclusion in Faculty Work Comprehensive List by an authorized administrator of Dordt Digital Collections. For more information, please contact ingrid.mulder@dordt.edu. 


\title{
Photocatalytic Concrete Pavements: Laboratory Investigation of NO Oxidation Rate Under Varied Environmental Conditions
}

\author{
Abstract \\ Concrete pavements containing $\mathrm{TiO}_{2}$ can be used for air pollution control by oxidizing NOX under UV- \\ bearing sunlight. This study employed a bench-scale photoreactor to estimate NO oxidation rates for \\ varied environmental conditions. Rates correlated positively with NO inlet concentration and irradiance \\ and negatively with relative humidity. No correlation occurred with flow rate. A decrease in slab moisture \\ (previously unstudied) positively correlated with NO oxidation rate at $0-2 \%$ loss of saturated mass, but \\ negatively correlated at losses greater that $2 \%$. Although prior researchers deemed temperature \\ insignificant, data indicated a positive correlation. Overall, rates ranged from $9.8-64 \mathrm{nmol} \cdot \mathrm{m}^{-2} \cdot \mathrm{s}^{-1}$. \\ Keywords \\ photocatalytic pavement, air pollution mitigation, nitrogen oxides, titanium dioxide, photoreactor bench- \\ scale study \\ Disciplines \\ Construction Engineering and Management \\ Comments \\ Copyright (c) 2015 Elsevier \\ http://www.sciencedirect.com/science/article/pii/S0950061815304281
}

This article is available at Dordt Digital Collections: https://digitalcollections.dordt.edu/faculty_work/456 
Photocatalytic concrete pavements: Laboratory investigation of NO oxidation rate under varied

environmental conditions

3

4

5

6

7

8

9

10

11

12

13
Abstract

Concrete pavements containing $\mathrm{TiO}_{2}$ can be used for air pollution control by oxidizing $\mathrm{NO}_{\mathrm{X}}$ under UVbearing sunlight. This study employed a bench-scale photoreactor to estimate NO oxidation rates for varied environmental conditions. Rates correlated positively with NO inlet concentration and irradiance and negatively with relative humidity. No correlation occurred with flow rate. A decrease in slab moisture (previously unstudied) positively correlated with NO oxidation rate at $0-2 \%$ loss of saturated mass, but negatively correlated at losses greater that $2 \%$. Although prior researchers deemed temperature insignificant, data indicated a positive correlation. Overall, rates ranged from $9.8-64 \mathrm{nmol} \cdot \mathrm{m}^{-2} \cdot \mathrm{s}^{-1}$.

\section{Keywords}

Photocatalytic pavement; air pollution mitigation; nitrogen oxides; titanium dioxide; photoreactor bench-scale study

\section{Introduction}

Within the United States, an estimated 48 million people live within $90 \mathrm{~m}$ of a four-lane (or larger) highway, railroad, or airport (Primary National Ambient Air Quality Standards for Nitrogen Dioxide: Proposed Rule, 2009). This population segment is susceptible to negative health effects associated with $\mathrm{NO}_{2}$ exposure (Brauer et al., 2002; Brunekreef et al., 1997; Finkelstein et al., 2004; Garshick et al., 2003; Kim et al., 2004). Nitrogen dioxide $\left(\mathrm{NO}_{2}\right)$, a motor vehicle air pollutant, is regulated by the United States Environmental Protection Agency (USEPA). The agency's justification for this regulation has recently been confirmed with evidence from multiple epidemiologic studies associating short-term $\mathrm{NO}_{2}$ exposure and adverse respiratory symptoms, particularly in children and those affected with asthma (USEPA, 2008b). 
$\mathrm{NO}_{2}$ falls within a group of highly reactive oxides of nitrogen commonly known as $\mathrm{NO}_{x}$. Nitric oxide

24 (NO) accounts for $95 \%$ of $\mathrm{NO}_{x}$ emissions (USEPA, 2001). This pollutant is freely oxidized to $\mathrm{NO}_{2}$ in the 25 atmosphere; hence, the efforts to abate $\mathrm{NO}_{2}$ pollution target $\mathrm{NO}$ emissions. In fact, due to the high

26 reactivity of the various $\mathrm{NO}_{x}$ species, USEPA assumes all $\mathrm{NO}_{x}$ in emissions estimates to be in the form of

$27 \mathrm{NO}_{2}$ (USEPA, 2001). USEPA employs various mechanisms in an effort to minimize $\mathrm{NO}_{x}$ exposure (e.g.,

28 improvements in public transportation, establishment of lanes for high occupancy vehicles, facilitating

29 non-automobile travel, and promulgation of tailpipe $\mathrm{NO}_{\mathrm{x}}$ emissions standards) (Clean Air Act, 2008;

30 USEPA, 2007). $\mathrm{NO}_{x}$ mitigation strategies are not exempt from the law of diminishing marginal returns;

31 therefore, in addition to efficiently applying conventional mechanisms, novel technologies should be

32 considered. These technologies may yield higher levels of pollution reduction per dollar spent.

33 Photocatalytic pavements represent one of these novel approaches. When exposed to sunlight and in the

34 presence of a low concentration of water molecules, titanium dioxide $\left(\mathrm{TiO}_{2}\right)$ contained within these

35 pavements generates hydroxyl radicals $\left({ }^{\circ} \mathrm{OH}\right)$, a powerful oxidizing agent. These radicals promote the

36 oxidation of a variety of organic and inorganic pollutants. Notably, the photocatalytic property of these

37 pavements results in oxidation of $\mathrm{NO}_{x}$ to $\mathrm{NO}_{3}^{-}$(Figure 1). 


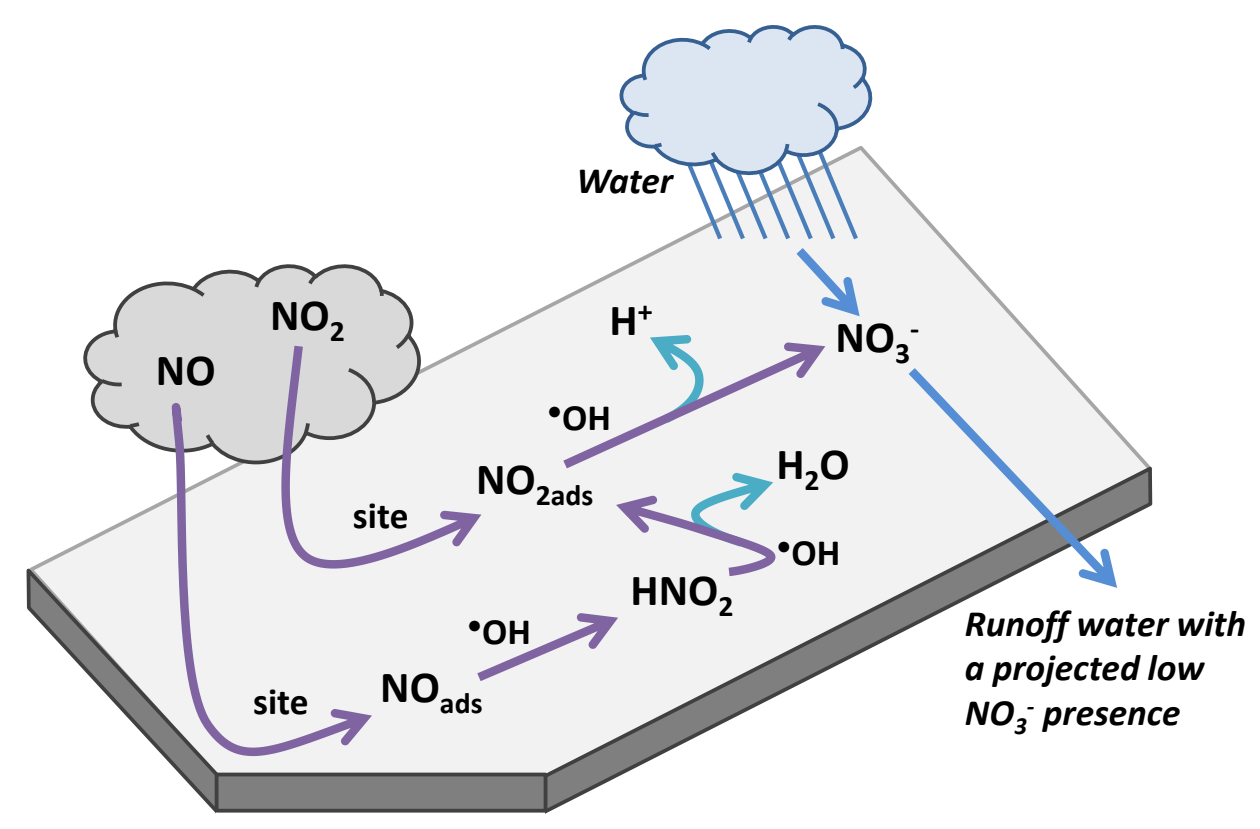

Figure 1. Photocatalytic oxidation of $\mathrm{NO}$ and $\mathrm{NO}_{2}$ by pavement containing $\mathrm{TiO}_{2}$ (partially adapted from targeted area will require an extensive development of what is known about NO oxidation rates under varied environmental conditions. In an effort to provide this new knowledge, various researchers have published accounts of laboratory studies that evaluated photocatalytic pavement specimens within a photoreactor, an experimental apparatus that allows for the control of various environmental conditions (Dylla et al., 2010; Hüsken et al., 2009; Murata \& Tobinai, 2002). Independent environmental variables

47 investigated have included NO concentration, irradiance, test gas flow rate, and relative humidity. Although material variables, such as $\mathrm{TiO} 2$ concentration and type, will also play a role, environmental variable results presented to date have not brought about a consensus in terms of the range in NO oxidation rates that can be expected. Murata et al. (2000), Hüsken et al. (2009), and Ballari et al. (2011) each suggest that NO oxidation rates positively correlate with NO concentration in situations when the 
conditions $\left(1.0 \mathrm{ppmv}, 10 \mathrm{~W} \cdot \mathrm{m}^{-2}, 3 \mathrm{~L} \cdot \mathrm{min}^{-1}, 50 \% \mathrm{RH}\right)$ the range in oxidation rates was wide $\left(38-84 \mathrm{nmol} \cdot \mathrm{m}^{-}\right.$ $\left.{ }^{2} \cdot \mathrm{s}^{-1}\right)$. Similarly, publications have noted a positive correlation between irradiance and oxidation rate, but at $10 \mathrm{~W} \cdot \mathrm{m}^{-2}$ calculated oxidation rates were $87 \mathrm{nmol} \cdot \mathrm{m}^{-2} \cdot \mathrm{s}^{-1}$ for Murata et al. (2000) and $24 \mathrm{nmol} \cdot \mathrm{m}^{-2} \cdot \mathrm{s}^{-1}$ for Hüsken et al. (2009). Both Murata et al. (2000) and Hüsken et al. (2009) observed a negative correlation between relative humidity and oxidation rate; however, at 50\% relative humidity oxidation rates differed by $22 \mathrm{nmol} \cdot \mathrm{m}^{-2} \cdot \mathrm{s}^{-1}$. These prior studies have assumed that water vapor from the atmosphere serves as both the source of ${ }^{\bullet} \mathrm{OH}$ required for photocatalytic oxidation and the material which adsorbs on the surface and blinds photocatalytically active sites. Yet, given the porous nature of cementitious mixtures, water contained within a pavement could also serve as a ${ }^{\bullet} \mathrm{OH}$ source and blinding material. At the time of placement, these pores can become filled with water. As hydration occurs and pores become filled with air, water that is available as a ${ }^{\bullet} \mathrm{OH}$ source and blinding material decreases. Therefore, a decrease in moisture contained in the slab could lead to a either an increase or decrease in the NO oxidation rate of the slab; however, no lab investigation has tested this hypothesis. Hüsken et al. (2009) observed a positive correlation between percent NO removal (as opposed to NO oxidation rate) and flow rate (slope of a linear fit was less than -10). This finding was also reported in Ballari et al. (2010), however in this case slope was only slightly less than -1. Finally, a review of the fundamentals of heterogeneous catalysis indicates that, due to the fact that reactant adsorption is dependent on temperature, oxidation rate appears to be correlated with temperature (Herrmann, 2010). However, literature pertaining to photocatalytic pavements is both vague and contradictory in terms of the relationship between slab temperature and NO oxidation, with one source asserting that oxidation rate increases with an increase in temperature (Beeldens et al., 2011) and another reporting a decrease in oxidation rate with increased temperature (Chen \& Chu, 2011).

Consequently, this study employed TX Active mortar slabs and a photoreactor to evaluate the change in NO oxidation rate that occurs with changes in NO concentration, irradiance, test gas flow rate, relative 
77 humidity, decrease in slab moisture, or temperature. In instances when published photocatalytic

78 pavement data existed, the data collected in this study was compared with data published by other

79 researchers in order to draw conclusions in regards to the range of NO oxidation rates that could be

80 expected and the variation that occurs between specimens.

\section{2. Materials and Methods}

\section{2.1. Photocatalytic Mortar Slab Preparation and Cleaning}

Three photocatalytic mortar slabs were used to evaluate this study's objectives. These slabs measured $152 \mathrm{~mm}$ (6 in) $\times 152 \mathrm{~mm}$ (6 in) $\times 25 \mathrm{~mm}$ (1 in). For this study, the researchers used a commercially-available cement that contains $\mathrm{TiO}_{2}$ (TX Active, Essroc Italcementi Group, Nazareth, PA). Although, the $\mathrm{TiO}_{2}$ content in this cement was not provided by the manufacturer, within patents governing photocatalytic cements,

$87 \mathrm{TiO}_{2}$ content ranges from $2-10 \%$ by mass (Paz, 2010). The proportions of the cement (TX Active or Type I), water, and fine aggregate (ASTM C778 standard sand, U.S. Silica Co., Frederick, MD) were recorded as $624 \mathrm{~kg} \cdot \mathrm{m}^{-3}\left(1052 \mathrm{lb} \cdot \mathrm{yd}^{-3}\right), 262 \mathrm{~kg} \cdot \mathrm{m}^{-3}\left(442 \mathrm{lb} \cdot \mathrm{yd}^{-3}\right)$, and $1412 \mathrm{~kg} \cdot \mathrm{m}^{-3}\left(2380 \mathrm{lb} \cdot \mathrm{yd}^{-3}\right)$ respectively. Given the cement proportion and the range in $\mathrm{TiO}_{2}$ cement content above, estimated $\mathrm{TiO}_{2}$ content of the mortar was $12.5-62.4 \mathrm{~kg} \cdot \mathrm{m}^{-3}$. Given the small volume of the slabs constructed, the mix did not include coarse aggregate. Except for the coarse aggregate, the relative proportions of materials used to manufacture the laboratory mortar slabs were similar to that of a pavement section placed at a field site, which will be evaluated in future research efforts (citation removed to ensure blind review). Particular care was taken to use the same water-to-cement ratio for both lab and field mixtures. During the placement process, a paste of water and photocatalytic cement coats aggregates and when hardened forms the surface that is exposed to pollutants. To manufacture the slabs, a two-lift procedure was used with equal volumes of a Type I cement bottom lift followed by a TX Active photocatalytic cement top lift. A possibility exists that excess vibration and surface finishing could draw water to the surface, thereby reducing the $\mathrm{TiO}_{2}$ 
101 with a mallet and leveled with use of a screed. Following placement, a damp cloth and plastic sheet were

102 laid over the slab surface for a 24-h curing period. Following this initial curing period, the slabs were 103 removed from the forms and placed in a $100 \%$ relative humidity room for the duration of a $14-d$ curing 104 period.

105

Prior to evaluating NO oxidation rates (described in Section 2.3), slabs were cleaned by immersion in water (Type I reagent grade) for $2 \mathrm{~h}$ and oven-dried at $60^{\circ} \mathrm{C}\left(140^{\circ} \mathrm{F}\right)$ for $20 \mathrm{~h}$. This procedure was similar to that specified by the International Organization for Standardization (ISO) standard 22197-1:2007(E); this standard governs evaluation of NO removal by photocatalytic materials (ISO, 2007).

\subsection{Experimental Apparatus}

A flow-through poly(methyl methacrylate) (PMMA, i.e., plexiglass) photoreactor served as the primary component of the experimental apparatus. Figure 2 provides a schematic of the photoreactor, along with the NO test gas supply system, UV-A light source, and NO/NOx monitor. The international standard, ISO 22197-1:2007(E), provided information on the construction and operation of the setup (ISO, 2007). The test gas supplied to the photoreactor was a mixture of breathing air (Grade D, Airgas USA, LLC, North Central Region, West Chicago, IL) and $51.6 \pm 1 \%$ ppmv NO balanced in nitrogen (EPA protocol gas, Praxair, Inc., Danbury, CT) adjusted to a NO concentration of $0.11-1.0$ ppmv, relative humidity of $10-70 \%$, and flow rate of 1.5-5.0 L.min ${ }^{-1}$. A UV-A light (XX-15BLB, Ultra-Violet Products, LLC, Upland, CA), directed at the UV-A-transparent optical window located at the top of the photoreactor, activated the photocatalytic properties of the mortar slab. The primary emissions spectrum peak from the light was $365 \mathrm{~nm}$. At the location of the slab surface, the irradiance at $365 \mathrm{~nm}$ was measured to be $0.22-1.5 \times 10^{1} \mathrm{~W} \cdot \mathrm{m}^{-2}$ using 365 nm UV sensor and radiometer (CX-365 and VLX-3W, Vilber Lourmat, Marne-la-Vallée, France). Except for instances when temperature was investigated as an independent variable, slab temperature was room temperature (approximately $22^{\circ} \mathrm{C}$ ). 
As displayed in Figure 3, within the reactor, $25 \mathrm{~mm}$ (1 in) wide PMMA spacers secured the slab's

125 position and were set at a height that was either flush with or less than $2 \mathrm{~mm}$ below the slab surface.

126 Within the $300 \mathrm{~mm}$ long reactor, the gas flowed over the slab through a cross section with a width of 150

$127 \mathrm{~mm}(6 \mathrm{in})$ and a height $(H)$ of approximately $6 \mathrm{~mm}(0.25 \mathrm{in})$. Turbulent airflow over the slab would

128 introduce additional variability in the test. Using the approach detailed in Hüsken et al. (2009), Reynolds

129 number $(R e)$ was calculated to be 42.6 using an air kinematic viscosity of $1.54 \times 10^{-5} \mathrm{~m}^{2} \cdot \mathrm{s}^{-1}\left(1.66 \times 10^{-5} \mathrm{ft}^{2} \cdot \mathrm{s}^{-}\right.$

$\left.130{ }^{1}\right)$ and an air flow rate of $3 \mathrm{~L} \cdot \mathrm{min}^{-1}\left(0.8 \mathrm{gal} \cdot \mathrm{min}^{-1}\right)$. The length $\left(L_{d}\right)$ for a parabolic velocity profile in the

131 photoreactor was estimated to be approximately $27.1 \mathrm{~mm}(1.1 \mathrm{in})$ by the following equation: $L_{d}=0.1 \cdot R e \cdot H$.

132 The estimated length was slightly longer than the length of the PMMA spacers, which indicates that

133 approximately $1.1 \%$ of the slab surface did not have a fully developed parabolic velocity profile. At $3 \mathrm{~L} \cdot \mathrm{min}^{-}$

$134{ }^{1}$, theoretical retention time of the test gas within the photoreactor was estimated to be $38 \mathrm{~s}$. Theoretical

135 retention time of the test gas in the volume above the slab at $3 \mathrm{~L} \cdot \mathrm{min}^{-1}$ was estimated to be $2.7 \mathrm{~s}$.

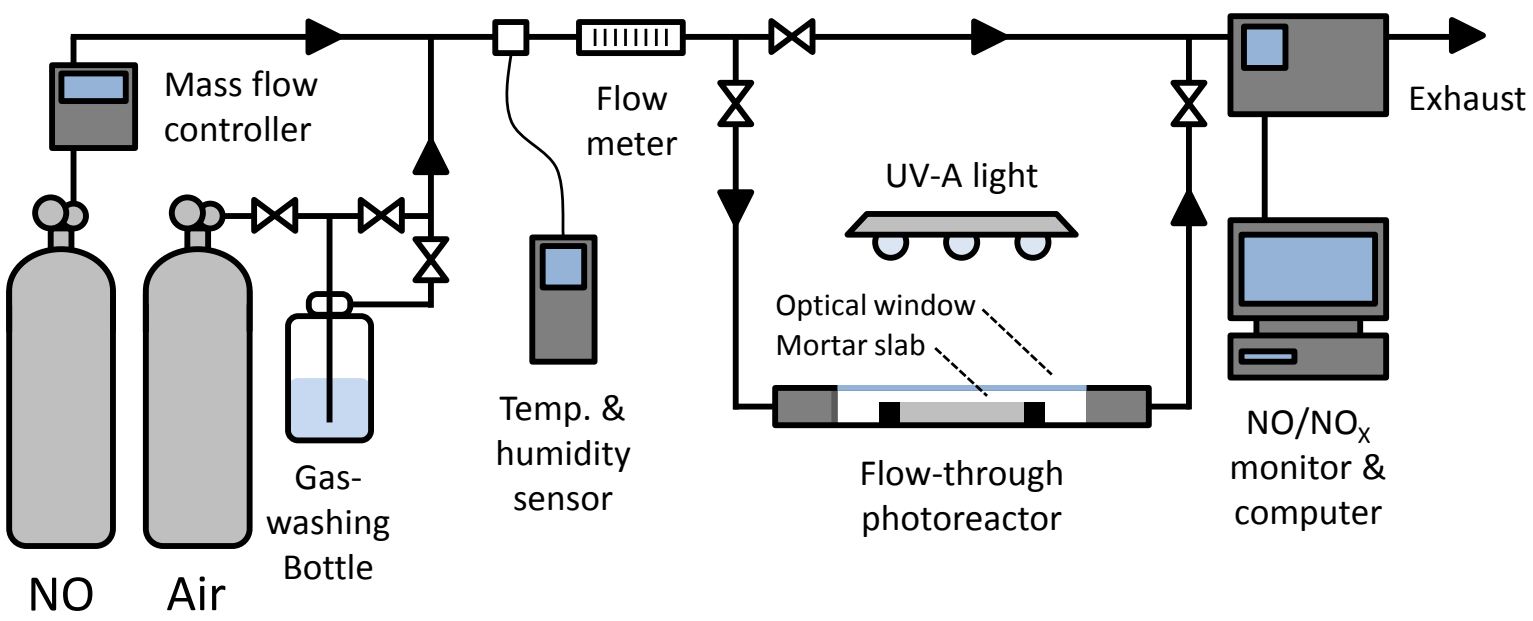




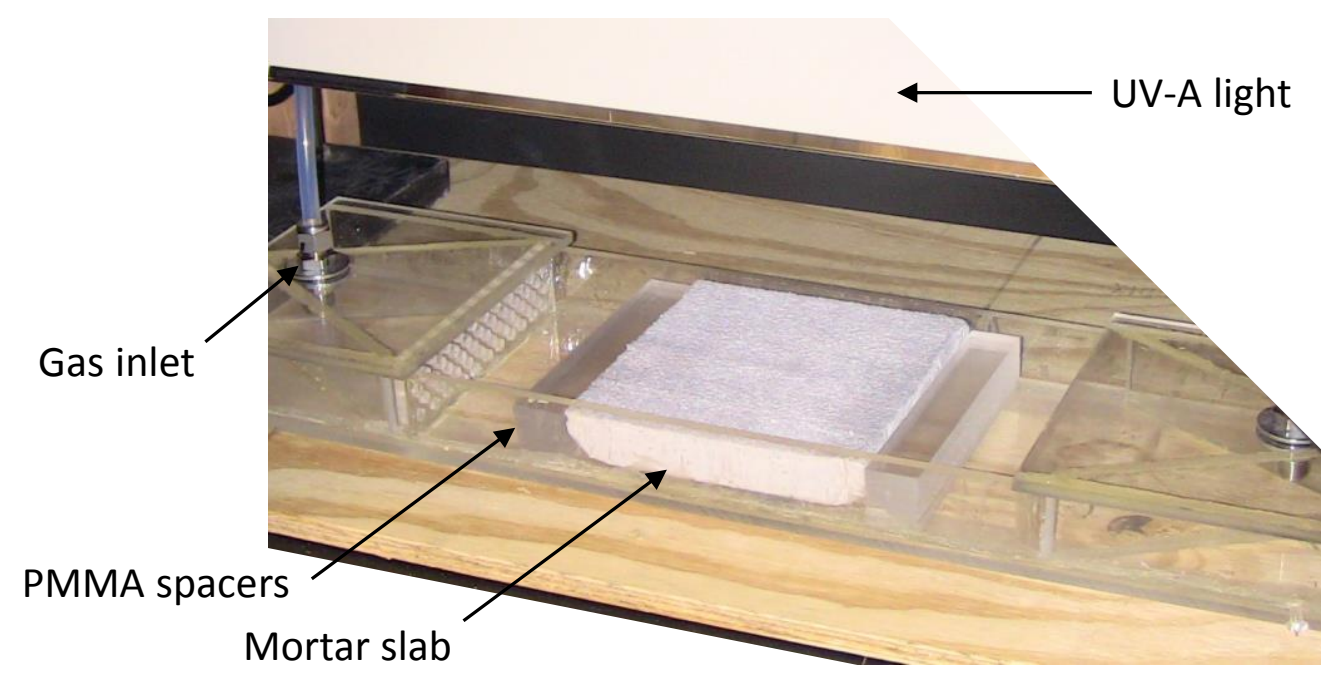

Figure 3. Photograph of photoreactor and mortar slab (optical window removed to facilitate viewing).

A NO/NOx monitor, (Model 410 Nitric Oxide Monitor and Model $401 \mathrm{NO}_{2}$ Converter, 2B Technologies,

141 Inc., Boulder, CO), completed the experimental apparatus. The monitor recorded the gas concentrations

142 at $10 \mathrm{~s}$ intervals and was set to measure either $\mathrm{NO}$ or $\mathrm{NO}_{\mathrm{x}}$. Unlike chemiluminescence instruments, which

143 detect the light produced when NO reacts with ozone $\left(\mathrm{O}_{3}\right)$, the Model 410 measures the change in UV

144 absorbance at $254 \mathrm{~nm}$ when $\mathrm{O}_{3}$ is consumed upon reaction with NO. UV absorbance is an absolute

145 method; therefore, the analyzer requires calibration annually to correct for non-linearity that exists in the

146 photodiode response and associated electronics.

\section{2.3. Operational Procedure}

148 Operation of the experimental apparatus was divided into two phases: parameter setting and testing.

149 While in the parameter setting phase, the test gas flowed through the photoreactor; however, the slab

150 was not irradiated by UV light. This phase was used to set airflow rate, relative humidity, and pollutant

151 concentration and lasted for approximately 10 minutes. After adjusting parameters to desired values, gas

152 flow was maintained through the photoreactor for a period sufficient to reach steady-state conditions. 
The testing period comprised two steps during which the UV light was turned off and on and 154 concentrations of $\mathrm{NO}$ and $\mathrm{NO}_{x}$ were measured. Figure 4 illustrates the UV on and off measurement cycle. 155 Time to complete this cycle was limited to 60 minutes to minimize the possible influence of slab 156 degeneration (e.g., due to the adsorption of reaction products) on collected data. Of note, a gap occurred 157 between measurement of UV light on and off segments. The change in concentration that occurred when 158 the light was turned on or off was not instantaneous. The period between measurements permitted time 159 for concentration stabilization after each parameter change. In some instances, the time gap was not 160 sufficient for concentration stabilization. When analyzing the data strings, these values were identified 161 and removed. The study also did not evaluate adsorption of NO that could occur on the slab or on other 162 surfaces within the photoreactor; rather, in similarity to other studies, this research focused on NO 163 removal that occurred as result of irradiance by UV light (Ballari et al., 2011, Hüsken et al. 2009).

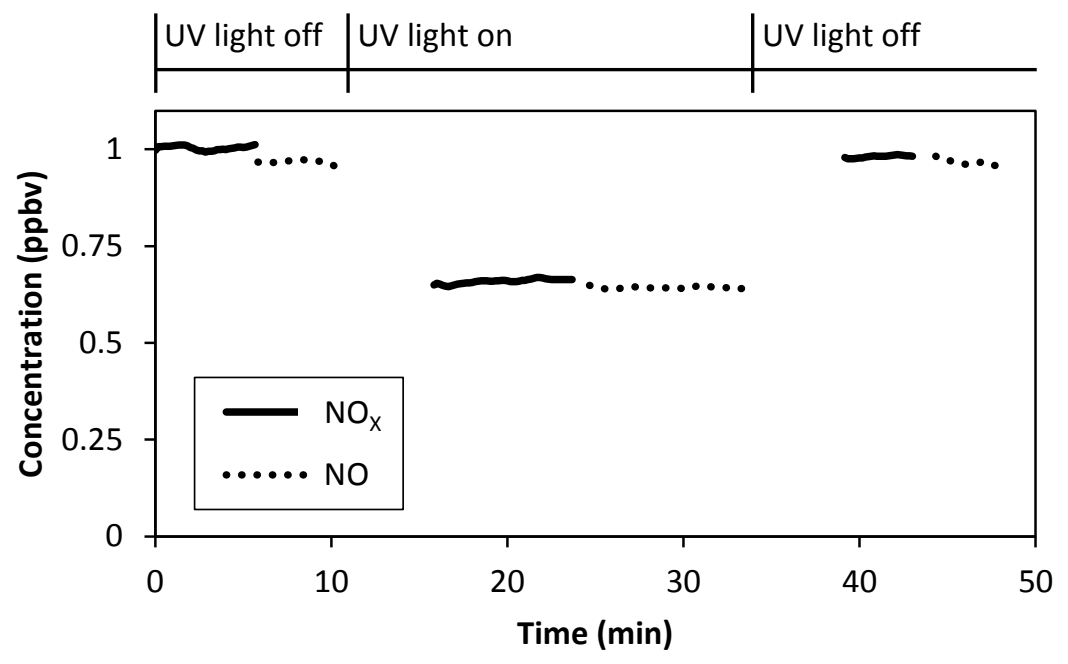
Figure 4. Typical $\mathrm{NO} / \mathrm{NO}_{\mathrm{x}}$ monitor data from testing procedure.

An alternative approach to test for photocatalytic oxidation is to measure NO concentration as the 167 test gas first flows through a bypass line and then is diverted to flow through the photoreactor. With this approach a portion of the decrease in concentration that occurs as the gas flows through the photoreactor could be due to adsorption on the slab and dilution by air leakage. Measuring the difference in 
170 concentration between UV-off and -on periods avoided these error sources and limits the source for a

171 change concentration to photo-oxidation and photo-dissociation. To evaluate whether photo-dissociation

172 occurred within the photoreactor, the researchers also evaluated a slab that was not manufactured with

173 photocatalytic cement (see Control in Table 1). A two-tailed $t$-test, assuming unequal variances, did not

174 find evidence of a significant difference between average UV-off and UV-on NO concentration at $90 \%$

175 confidence $(t=3.019, \mathrm{df}=4, p=0.039)$.

\section{2.4. Variable Control and Measurement for Completed Tests}

177 To evaluate the objectives listed above, the study collected data on the NO oxidation rates of 178 photocatalytic mortar slabs under varied environmental conditions. In some cases, $\mathrm{NO}_{\mathrm{x}}$ oxidation rates 179 were also collected. The following environmental variables were considered: NO concentration ( $C_{U V}$ off $)$, 180 irradiance (Irrad.), test gas flow rate $(Q)$, relative humidity $(R H)$, decrease in slab moisture, and slab 181 temperature (Temp). Table 1 presents values of these variables for the tests of NO concentration, 182 irradiance, test gas flow rate, relative humidity, and slab temperature. For these tests, at the initial 183 measurement (Test ID 0), all variables were set at the values specified by ISO 22197-1:2007(E) (i.e., CUv off $\left.184=1.0 \mathrm{ppmv}, \mathrm{Irrad} .=10 \mathrm{~W} \cdot \mathrm{m}^{-2}, Q=3.0 \mathrm{~L} \cdot \mathrm{min}^{-1}, \mathrm{RH}=50 \%\right)$. In subsequent tests, each independent variable 185 was decreased or increased from the ISO-specified values in order to evaluate the change in NO and $\mathrm{NO}_{\mathrm{x}}$ 186 oxidation. To facilitate comparison to other published work, selected values of these variables were 187 similar to values reported in said studies. 
Table 1. Environmental conditions and results of tests completed.

\begin{tabular}{|c|c|c|c|c|c|c|c|c|c|c|c|c|c|c|c|c|}
\hline \multirow{4}{*}{ Test \# } & \multirow{4}{*}{ Slab ID } & \multicolumn{9}{|c|}{ Environmental conditions } & \multicolumn{6}{|c|}{ Results } \\
\hline & & \multirow[t]{3}{*}{ Description } & \multicolumn{4}{|c|}{$\begin{array}{c}\text { Cuv off } \\
\text { (ppmv) }\end{array}$} & \multirow[t]{3}{*}{$\begin{array}{c}\text { Irrad. } \\
\left(\mathrm{W} \cdot \mathrm{m}^{-2} \times 10^{1}\right)\end{array}$} & \multirow[t]{3}{*}{$\begin{array}{c}Q \\
\left(L \cdot \mathrm{min}^{-1}\right)\end{array}$} & \multirow[t]{3}{*}{$\begin{array}{l}\mathrm{RH} \\
(\%)\end{array}$} & \multirow[t]{3}{*}{$\begin{array}{c}\text { Slab temp. } \\
\left({ }^{\circ} \mathrm{C}\right)\end{array}$} & \multicolumn{4}{|c|}{$\begin{array}{l}\text { Cuv on } \\
\text { (ppmv) }\end{array}$} & \multicolumn{2}{|c|}{$\begin{array}{l}\text { Oxidation rate } \\
\left(\mathrm{nmol} \cdot \mathrm{m}^{-2} \cdot \mathrm{s}^{-1}\right)\end{array}$} \\
\hline & & & \multicolumn{2}{|c|}{$\mathrm{NO}_{\mathrm{x}}$} & \multicolumn{2}{|c|}{ NO } & & & & & \multicolumn{2}{|c|}{ NO $_{x}$} & \multicolumn{2}{|c|}{ NO } & \multirow[t]{2}{*}{$\mathrm{NO}_{\mathrm{x}}$} & \multirow[t]{2}{*}{ NO } \\
\hline & & & $\mathbf{x}$ & s & $\mathbf{x}$ & s & & & & & $\mathbf{x}$ & s & $\mathbf{x}$ & s & & \\
\hline 0 & & Control & & & 1.1 & 0.00067 & 1.0 & 3.0 & 50 & $22^{\mathrm{i}}$ & & & 1.1 & 0.0033 & & 0.36 \\
\hline 0 & 1 & Initial & 1.0 & 0.0039 & 1.0 & 0.0046 & 1.0 & 3.0 & 50 & $22^{\mathrm{i}}$ & 0.71 & 0.0022 & 0.64 & 0.00054 & 34 & 42 \\
\hline 1 & 1 & $\Delta$ conc. & 0.12 & 0.014 & 0.11 & 0.011 & 1.0 & 3.0 & 50 & $22^{i}$ & 0.068 & 0.00062 & 0.043 & 0.0019 & 6.5 & 9.8 \\
\hline 2 & 1 & $\Delta$ conc. & 0.31 & 0.013 & 0.30 & 0.010 & 1.0 & 3.0 & 50 & $22^{\mathrm{i}}$ & 0.19 & 0.00055 & 0.15 & 0.00063 & 15 & 19 \\
\hline 3 & 2 & $\Delta$ irrad. & 1.0 & 0.0030 & 1.0 & 0.0036 & 0.22 & 3.0 & 50 & $22^{i}$ & 0.93 & 0.00035 & 0.89 & 0.00030 & 7.5 & 10 \\
\hline 4 & 2 & $\Delta$ irrad. & 1.0 & 0.0054 & 1.0 & 0.012 & 0.40 & 3.0 & 50 & $22^{\mathrm{i}}$ & 0.88 & 0.00030 & 0.83 & 0.00031 & 11 & 15 \\
\hline 5 & 2 & $\Delta$ irrad. & 1.0 & 0.0015 & 1.0 & 0.0029 & 0.70 & 3.0 & 50 & $22^{i}$ & 0.88 & 0.0011 & 0.82 & 0.0015 & 15 & 20 \\
\hline 6 & 2 & $\Delta$ irrad. & 1.0 & 0.0060 & 1.0 & 0.0034 & 1.0 & 3.0 & 50 & $22^{i}$ & 0.86 & 0.0012 & 0.79 & 0.00041 & 17 & 25 \\
\hline 7 & 2 & $\Delta$ irrad. & 1.0 & 0.0049 & 1.0 & 0.0051 & 1.5 & 3.0 & 50 & $22^{\mathrm{i}}$ & 0.76 & 0.0013 & 0.69 & 0.0012 & 27 & 34 \\
\hline 8 & 1 & $\Delta Q$ & 1.0 & 0.020 & 1.0 & 0.016 & 1.0 & 1.5 & 50 & $22^{i}$ & 0.58 & 0.0018 & 0.51 & 0.00055 & 28 & 33 \\
\hline 9 & 1 & $\Delta Q$ & 1.0 & 0.0075 & 1.0 & 0.0068 & 1.0 & 5.0 & 50 & $22^{i}$ & 0.84 & 0.0036 & 0.79 & 0.00055 & 27 & 35 \\
\hline 10 & 1 & $\Delta \mathrm{RH}$ & 1.0 & 0.0054 & 1.0 & 0.011 & 1.0 & 3.0 & 10 & $22^{i}$ & 0.55 & 0.0021 & 0.50 & 0.0017 & 59 & 64 \\
\hline 11 & 1 & $\Delta \mathrm{RH}$ & 1.0 & 0.0037 & 1.0 & 0.0041 & 1.0 & 3.0 & 20 & $22^{i}$ & 0.59 & 0.0024 & 0.52 & 0.00083 & 52 & 61 \\
\hline 12 & 1 & $\Delta \mathrm{RH}$ & 1.0 & 0.0034 & 1.0 & 0.0044 & 1.0 & 3.0 & 70 & $22^{\mathrm{i}}$ & 0.80 & 0.0025 & 0.73 & 0.00069 & 23 & 28 \\
\hline 13 & 3 & $\Delta$ temp. & & & 1.0 & 0.0003 & 1.0 & 3.0 & 20 & 55 & & & 0.72 & 0.0041 & & 30 \\
\hline 14 & 3 & $\Delta$ temp. & & & 1.0 & 0.0024 & 1.0 & 3.0 & 20 & 49 & & & 0.72 & 0.0049 & & 31 \\
\hline 15 & 3 & $\Delta$ temp. & & & 1.0 & 0.0005 & 1.0 & 3.0 & 20 & 44 & & & 0.78 & 0.0060 & & 26 \\
\hline 16 & 3 & $\Delta$ temp. & & & 1.0 & 0.0010 & 1.0 & 3.0 & 20 & 39 & & & 0.70 & 0.0022 & & 25 \\
\hline 17 & 3 & $\Delta$ temp. & & & 1.0 & 0.00073 & 1.0 & 3.0 & 20 & 36 & & & 0.69 & 0.0029 & & 27 \\
\hline 18 & 3 & $\Delta$ temp. & & & 0.92 & 0.0017 & 1.0 & 3.0 & 20 & 34 & & & 0.70 & 0.0016 & & 22 \\
\hline 19 & 3 & $\Delta$ temp. & & & 0.92 & 0.0013 & 1.0 & 3.0 & 20 & 32 & & & 0.73 & 0.0054 & & 18 \\
\hline 20 & 3 & $\Delta$ temp. & & & 0.92 & 0.0077 & 1.0 & 3.0 & 20 & 19 & & & 0.73 & 0.0079 & & 19 \\
\hline 21 & 3 & $\Delta$ temp. & & & 0.88 & 0.0019 & 1.0 & 3.0 & 20 & 21 & & & 0.71 & 0.0013 & & 17 \\
\hline 22 & 3 & $\Delta$ temp. & & & 0.94 & 0.0018 & 1.0 & 3.0 & 20 & 22 & & & 0.78 & 0.0022 & & 16 \\
\hline 23 & 3 & $\Delta$ temp. & & & 1.0 & 0.0018 & 1.0 & 3.0 & 20 & 7.1 & & & 0.85 & 0.0041 & & 13 \\
\hline 24 & 3 & $\Delta$ temp. & & & 1.0 & 0.0013 & 1.0 & 3.0 & 20 & 13 & & & 0.81 & 0.0021 & & 16 \\
\hline 25 & 3 & $\Delta$ temp. & & & 1.0 & 0.0011 & 1.0 & 3.0 & 20 & 15 & & & 0.81 & 0.0042 & & 14 \\
\hline
\end{tabular}




\subsubsection{NO concentration, irradiance, test gas flow rate, and relative humidity}

Needle valves and a mass flow controller permitted control of NO concentration, test gas flow rate, and relative humidity. To control irradiance the distance between the UV light and photoreactor optical window was varied until the target value was observed on the radiometer at the height of the slab surface.

\subsubsection{Slab temperature}

Prior to evaluation in the photoreactor, a pre-cleaned slab (procedure in Section 2.1) was brought to an initial temperature that was either above or below room temperature. To obtain this initial temperature, a slab was placed in either an oven $\left(60^{\circ} \mathrm{C}\right)$ or a refrigerator $\left(2-4^{\circ} \mathrm{C}\right)$ for a period of $2 \mathrm{~h}$. After removal from the oven or refrigerator, the slab was immediately loaded into the photoreactor. An infrared thermometer (15-077-966, Thermo Fisher Scientific, Waltham, MA) recorded temperature at 5 points on the slab surface (the slab center and the center of each quadrant) immediately prior to and after photoreactor evaluation. If slab temperature was greater than room temperature, photocatalytic evaluation began after temperature recording. When slab temperature is less than the test gas temperature $\left(22^{\circ} \mathrm{C}\right)$, the possibility of water vapor condensation-which would blind photocatalytically active sties-must be considered because this condensation would falsely indicate reduced photoactivity. This error can be minimized by ensuring that the lowest slab temperature is substantially above the dew point temperature of the test gas. To create a substantial difference between temperatures, the researchers selected a $20 \%$ relative humidity for the test gas (dew point $=-2^{\circ} \mathrm{C}$ ). As a result, even if the test gas air cooled $5^{\circ} \mathrm{C}$ as it flowed over a cool slab, relative humidity would only increase to $60 \%$ and saturation of the test gas would not occur. To further minimize this potential error, the researchers attempted to evaporate condensed water by using valves to reduce the test gas relative humidity to $0 \%$ for a 10 minute period. Following this period, the UV light was turned on, relative humidity was increased to the target value (20\%), and photocatalytic evaluation began. The possibility exists that the effort to 
213 avoid error by water condensation was unsuccessful. This possibility was evaluated by comparing the

214 slope of the NO oxidation rate versus temperature line for observations below and above $22^{\circ} \mathrm{C}$ (Section

215 3.1.6). It must also be noted, that in this portion of the study, the researchers sought to ensure that water

216 vapor density remained constant throughout the tests, rather than relative humidity. To achieve this

217 goal, relative humidity was set in reference to the test gas temperature, which remained constant, rather

218 than the variable slab temperature.

Additional NO oxidation rate evaluations were completed in succession as the slab temperature

increased or decreased. Three sets of successive tests were recorded at the following temperature classifications: hot $\left(32-55^{\circ} \mathrm{C}\right.$, Test IDs $\left.13-19\right)$, warm $\left(19-22^{\circ} \mathrm{C}\right.$, Test IDs $\left.20-22\right)$, and cool $\left(7.1-15^{\circ} \mathrm{C}\right.$, Test

222 IDs 23-25) as shown in Table 1. Conducting successive tests could lead to a decrease in reactivity over 223 time; therefore, the testing period was reduced such that the total testing time for the hot, warm, and 224 cool classifications was 90,40 , and 40 minutes, respectively. Slab temperature was not measured at the 225 midpoint of each test; instead, this value was estimated. The temperature and time data collected during 226 the hot $(n=40)$, warm $(n=20)$, and cold $(n=20)$ sets of successive tests fit power law curves when 227 adjusted for asymptotic values $\left(R^{2}>0.95\right.$ for each set). For example, temperature for the hot classification

228 was estimated using the following equation: $T=5 \times 10^{-5} \cdot[(t+647) / 1440]^{-16.76}+28(T=$ 229 temperature in ${ }^{\circ} \mathrm{C}, t=$ elapsed time in minutes, $\left.R^{2}=0.99\right)$. These curves were used to estimate 230 slab temperature at the midpoint of the photoreactor test.

\subsubsection{Decrease in slab moisture}

To evaluate the effect of a decrease in slab moisture, NO oxidation was periodically evaluated as water content decreased after starting at a saturated state. For these tests, NO concentration was set to 1.0

234 ppmv, flow rate to $3 \mathrm{~L} \cdot \mathrm{min}^{-1}$, relative humidity to $20 \%$ and UV-A irradiance to $10 \mathrm{~W} \cdot \mathrm{m}^{-2}$ at $365 \mathrm{~nm}$. In 235 similarity with the approach used in Section 2.4.2, a constant vapor density was ensured by setting relative 
236 humidity in reference to the test gas temperature. To achieve saturation, a slab was immersed in water

237 for $24 \mathrm{~h}$. To promote a decrease in slab moisture, the slab was placed in a $60^{\circ} \mathrm{C}$ oven. The slab was

238 periodically removed from this oven in order to measure slab mass and NO oxidation rate. Testing

239 continued for the duration of $48 \mathrm{~h}$. The decrease in slab moisture was presented as a percentage using

240 the mass at the point of saturation and the calculated moisture loss (i.e., the difference in mass at

241 saturation and at the point of photoreactor evaluation).

242 2.5. Presentation of Results

243 Other published works present NO removal as a percentage based on the difference between UV-off

244 and -on concentrations of NO. Percent removal data is in part a function of lab setup (e.g., slab

245 dimensions). Presenting results in this manner can lead to misperceptions if, for example, results are not

246 normalized by area. In this research results are presented as the average NO oxidation rate in the reactor

247 volume using the equation given by Minero et al. (2013):

248

NO oxidation rate $=\frac{P}{R \cdot T} \cdot \frac{Q}{A} \cdot C_{U V \text { off }} \cdot \ln \left(\frac{C_{U V \text { off }}}{C_{U V \text { on }}}\right)=\left[\frac{n m o l}{m^{2} \cdot s}\right]$

249 where,

$250 P=$ atmospheric pressure $=101.3 \mathrm{kPa}$,

$251 R=$ ideal gas constant $=8.314 \times 10^{-12} \mathrm{~m}^{3} \cdot \mathrm{kPa}^{\mathrm{n}} \mathrm{nmol}^{-1} \cdot \mathrm{K}^{-1}$,

$252 T=$ temperature $=[K]$,

$253 Q=$ volumetric flow rate $=\left[\mathrm{m}^{3} / \mathrm{s}\right]$

$254 A=$ slab surface area $=0.023 \mathrm{~m}^{2}$,

$255 C_{U V \text { off }}=$ NO concentration with $U V$ light off $=[p p m v]$, and

$256 C_{U V \text { on }}=$ NO concentration with UV light on $=[p p m v]$. 
The recorded test gas temperature was used to calculate oxidation rate for evaluations of NO

258 concentration, irradiance, flow rate, and relative humidity. Due to the low mass flow rate $\left(5.6 \times 10^{-5} \mathrm{~kg} \cdot \mathrm{s}^{-}\right.$

$\left.259{ }^{1}\right)$ and specific heat of air $\left(1.007 \mathrm{~kJ} \cdot \mathrm{kg}^{-1} \cdot{ }^{\circ} \mathrm{C}^{-1}\right)$, evaluations of slab temperature and slab moisture assumed that the test gas temperature was the same as the slab temperature.

\section{Results and Discussion}

\subsection{NO Oxidation Rate for Tests Completed}

Table 1 documents the environmental parameters and oxidation rate results of the tests completed

264 for this study. Of note, in each instance the value of $\mathrm{NO}$ oxidation rate is greater than that of $\mathrm{NO}_{\mathrm{x}}$ oxidation 265 rate. It could be expected that since the test gas supply to the reactor was nearly entirely comprised of $266 \mathrm{NO}$, then the NO and $\mathrm{NO}_{\mathrm{x}}$ removal values would be the same value. The discrepancy arises because NO is 267 not oxidized completely to $\mathrm{HNO}_{3}$. Rather, a portion of the gas is transformed to $\mathrm{NO}_{2} \cdot \mathrm{NO}_{2}$ that remained 268 in the gas stream was counted as part of the outlet $\mathrm{NO}_{\mathrm{x}}$ concentration. As a result, $\mathrm{NO}_{\mathrm{x}}$ removal measured 269 lower than NO removal.

In this study, all slabs were prepared with the same procedure, materials, and proportions but in 271 different batches. Review of Table 1 finds that although Tests IDs 0 and 6 were evaluated at the same 272 environmental conditions, the observed NO oxidation rate differed by $51 \%$ from the mean. This difference 273 may be due to several non-obvious factors within the mixing, placement, and curing steps. Prior research 274 also indicated that oxidation rate differences may occur between slab replicates. For example, Hüsken et

275 al. (2009) found that the percent difference of degradation rates for various replicates of photocatalytic 276 pavement materials varied from as low as $0 \%$ to as high as $63 \%$. Noting that differences did occur between 277 slab replicates, Figures 5 to 9 plot each independent variable versus NO oxidation rate for a selected slab. 278 To place this study's observations in context, overlaid on these plots are the data reported from previous 
279 research that investigated NO oxidation rates under differing environmental conditions (Ballari et al.,

280 2010; Ballari et al., 2011; Hüsken \& Brouwers, 2008; Hüsken et al., 2009; Murata et al., 2000).

\subsubsection{Influent NO Concentration}

282

Figure 5 indicates a correlation between inlet NO concentration and NO oxidation rate $\left(R^{2}=0.994\right)$

This correlation is also evident in the data from Murata et al. (2000) $\left(R^{2}=0.984\right.$ for $0-1.0 \mathrm{ppmv}, R^{2}=0.802$

284 for 0-5.0 ppmv), Hüsken and Brouwers (2008) and Hüsken et al. (2009) $\left(R^{2}=0.991\right)$, and Ballari et al. $285 \quad(2010)\left(R^{2}=0.882\right)$.

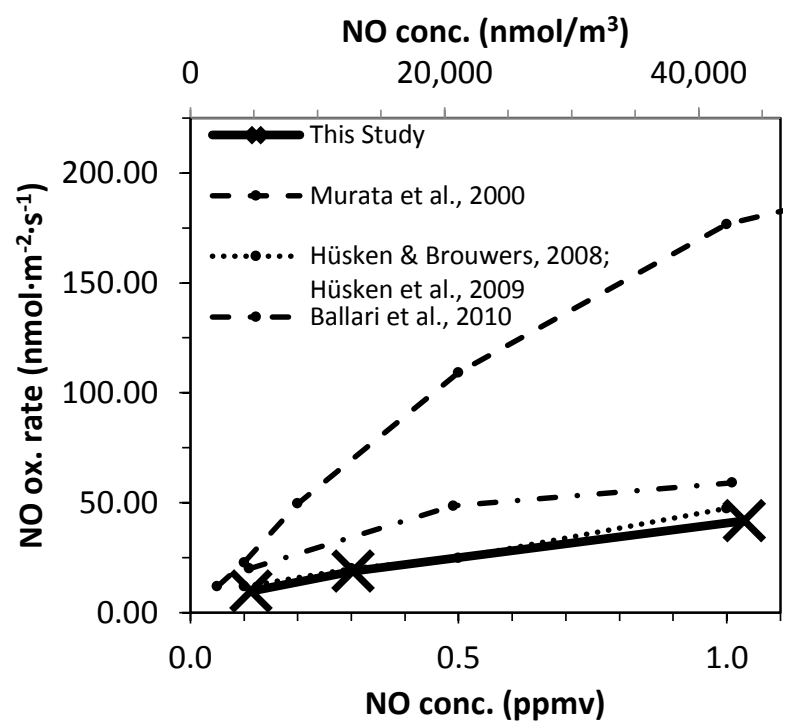
under which both reactants adsorb (e.g., $\mathrm{NO}$ and ${ }^{\bullet} \mathrm{OH}$ ) on the surface before a new molecule is formed.

291 For these type of reactions, kinetics typically fell into low-concentration and high-concentration 292 classifications. In the low-concentration classification, oxidation kinetics were first-order; whereas in the 293 high-concentration classification, oxidation kinetics were zero-order. As applied to NO degradation by 
294 photocatalytic pavements, this framework would indicate that, at high concentration, the rate of NO

295 oxidation would remain constant. A constant oxidation rate occurred because a finite number of active 296 sites were available for photocatalytic degradation. Once these sites were occupied, the rate of oxidation 297 did not increase. In contrast, while within the low-concentration classification, the active sites had not yet 298 been filled (Herrmann 1999).

For reactants adsorbed from aqueous phases, Herrmann (1999) indicated that a first-order kinetics 300 apply when concentration is less than $10^{-3} \mathrm{M}$ and zero-order kinetics apply at a concentration greater than $5 \times 10^{-3} \mathrm{M}$. These divisions have not been established for reactants adsorbed from a gas phase. Except for Ballari et al. (2010), which only had 3 observations, $t$-tests of the data presented in Figure 5 rejected a null hypothesis that slope equaled $0 \mathrm{nmol} \mathrm{m}{ }^{-2} \cdot \mathrm{s}^{-1} \cdot \mathrm{ppmv}^{-1}(p=<0.033)$. Based on this analysis, it is evident that this data falls into first-order oxidation kinetics, indicating that active sites have not been filled. For applications of photocatalytic pavement, a determination of where the breakpoint between first- and zero-order oxidation kinetics occurs is not necessary. Locations where these pavements may be installed can be assumed to have $\mathrm{NO}_{\mathrm{x}}$ concentrations near the National Ambient Air Quality Standards (NAAQSs) for $\mathrm{NO}_{2}$ (i.e., 53 and 100 ppbv) (Primary National Ambient Air Quality Standards for Nitrogen Dioxide: Final Rule, 2010). These values are substantially below the $1.0 \mathrm{ppmv}$ upper limit of the data analyzed; therefore, field applications can also be assumed to be characterized by first-order oxidation kinetics. 
317 markedly different that that of the authors'; therefore, material chacateristics are also likely to influence

318 the activity of photocatalytic pavements. More broadly, it can be concluded that because these slopes are

319 significantly different, a generalized assumption of the effect of NO concentration on NO oxidation rate

320 cannot be made. Instead, if a photocatalytic material is to be used in the field, it would be wise to complete

321 lab evaluations in order to project levels of oxidation that could be observed in the field.

\subsubsection{UV-A Irradiance}

Figure 6 indicates a positive correlation between UV-A irradiance and NO oxidation $\left(R^{2}=0.996\right)$. This

324 correlation is also evident in the data from Murata et al. (2000) $\left(R^{2}=0.910\right)$, Hüsken et al. (2009) $\left(R^{2}=\right.$ 325 0.940), and Ballari et al. (2011) $\left(R^{2}=0.986\right)$. This positive correlation exists because increased UV-A 326 irradiance on a photocatalytic surface increases the rate at which electron holes are created. An increase 327 in the rate of electron-hole generation results in the increased production rate of hydroxyl radicals, which 328 oxidize NO. Multiple publications report that the relationship between irradiance and pollutant oxidation 329 can be divided into two classifications. Although disagreement exists on the value of the division point 330 between classes $\left(10-250 \mathrm{~W} \cdot \mathrm{m}^{-2}\right)$, the publications note a linear relationship below the division point and 331 a non-linear relationship above this point (Herrmann et al., 2007; Jacoby et al., 1995; Kumar et al., 1995;

332 Lim et al., 2000; Obee \& Brown, 1995). Jacoby et al. (1995) explains that under the linear classification, 333 electron holes are filled by reactions with species on the photocatalytic surface (e.g., $\mathrm{OH}^{-}$) faster than by 334 recombination with excited electrons; in contrast, under the non-linear classification, holes are filled by 335 recombination at a faster rate than by reaction with other species. 


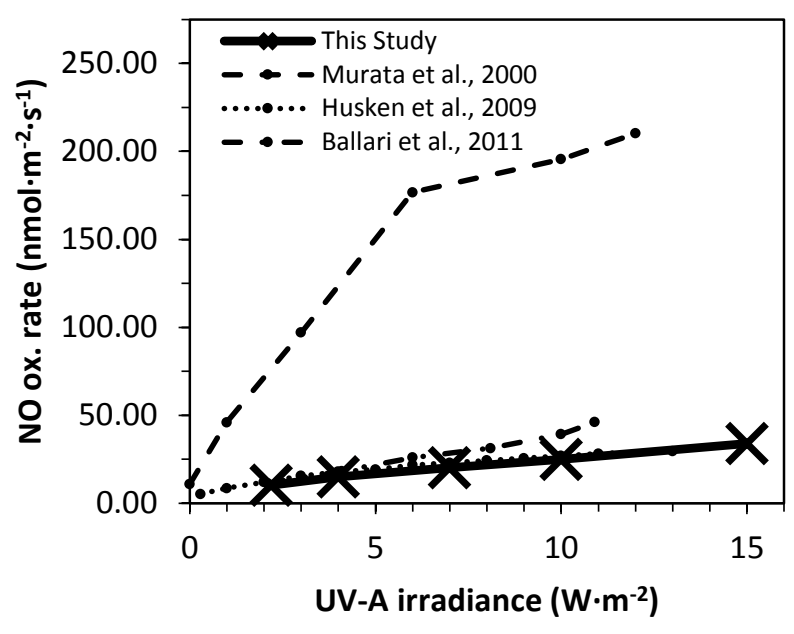

Figure 6. Effect of UV-A irradiance on NO oxidation rate [Ballari et al. (2011) collected data at 0.52 ppmv inlet NO concentration, all other studies used a 1.0 ppmv inlet NO concentration].

As noted above, a linear relationship is apparent when reviewing the data collected in this study $\left(R^{2}=\right.$

Hüsken et al. (2009) asserted power law relationship between percent NO removal and irradiance $(y=$ $\left.8.583 x^{0.431}, R^{2}=0.998\right)$ and concluded that linear behavior was limited to observations above $4 \mathrm{~W} \cdot \mathrm{m}^{-2}$. Linear behavior is also apparent in Ballari et al. (2011) $\left(R^{2}=0.986\right)$, but comparison of slopes did find a significant difference $(t=-8.462, d f=7, p=0.000)$. In contrast, the data from Murata et al. $(2000)$ appears non-linear $\left(R^{2}=0.910\right.$ for linear regression). Furthermore, a $t$-test comparing the slope of linear regression

347 lines between this data set and the authors' found a significant difference $(t=-5.672, d f=7, p=0.001)$. In 348 similarity with the conclusion reached in Section 3.1.1, this difference indicates that lab evaluation of a specific material selected for field application is warranted in order to assess its NO oxidation potential. 
monitoring network. In addition to knowledge of the mean UV-A irradiance, application of photocatalytic

354 pavement also requires knowledge on the change in irradiance during daylight hours. This knowledge is needed because in urban areas $\mathrm{NO}_{x}$ ambient concentration reportedly follows a diurnal pattern associated with traffic. Urban background monitoring in London, UK, found that $\mathrm{NO}_{2}$ peaks both in early

357 morning and late afternoon and $\mathrm{NO}$, which oxidizes quickly to $\mathrm{NO}_{2}$ during daylight hours, peaks in early 358 morning (Bigi \& Harrison, 2010). At these peaks, irradiance values are substantially lower than the mean 359 daytime value. For example, at the $40^{\text {th }}$ parallel north, which roughly runs through the center of the United 360 States, the difference between the typical mid-summer peak UV radiation and the radiation 4 hours earlier 361 in the day is more than $70 \%$ (Long et al., 1996). At present, oxidation rates at these low irradiance values 362 are quite low. To be effective at peak pollution hours, the ongoing efforts by other researchers to enhance $363 \mathrm{TiO}_{2}$ 's photo-induced reactivity must be incorporated into new formulations of photocatalytic pavements.

\subsubsection{Flow Rate}

A model utility test on the data collected in this study (presented in Figure 7) did not reject a null hypothesis that slope equaled $0 \mathrm{nmol} \cdot \mathrm{m}^{-2} \cdot \mathrm{s}^{-1} \cdot{ }^{\circ} \mathrm{C}^{-1}(t=0.118, d f=2, p=0.925)$, and therefore did not provide

367 evidence of a correlation between flow rate and NO oxidation rate. The same conclusion was found with 368 analysis of data from Hüsken and Brouwers (2008) and Hüsken et al. (2009) $(t=0.631, d f=2, p=0.642)$.

369 The independence of oxidation rate and flow rate aligns with the overall approach used by Hunger et. al 370 (2010) to model the oxidation of NO on photocatalytic concrete surfaces. Using a Langmuir-Hinshelwood 371 model and data collected with a photoreactor, Hunger et. al (2010) established that it is the conversion 372 of adsorbed species that limits the reaction rate, rather than mass transfer from the test gas to the sample 373 surface. 


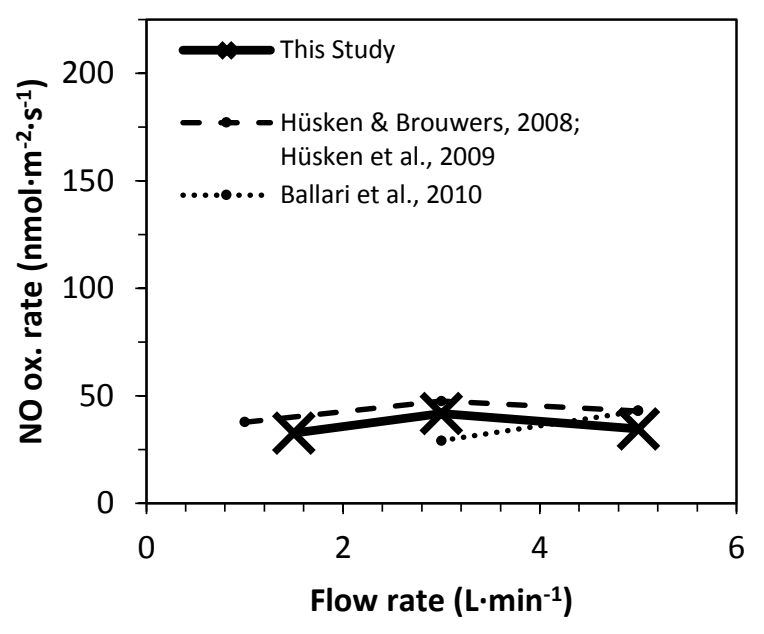

374

375

376

377 flow rates of $1.5,3$, and $5 \mathrm{~L} \cdot \mathrm{min}^{-1}$, respectively. Using these units, a negative relationship was evident

378 between flow rate and percent removal $(t=-27.718, d f=2, p=0.023)$. This relationship was also

379

380

381

382

383

384

385

386

387

388

389

390

Figure 7. Effect of flow rate on NO oxidation rate.

Results, presented in the form of percent NO removal, were determined to be 51,37 , and $21 \%$ for documented by other researchers (Ballari et al., 2010; Dylla et al., 2010; Hüsken \& Brouwers, 2008; Hüsken et al., 2009). These studies suggested that percent NO removal from a specific volume of test gas increases proportionally to the residence time over a photocatalytic surface because more time exists for pollutants to absorb and be oxidized at active sites. Overall, the lack of a correlation between flow rate and NO oxidation rate could simplify modeling efforts as stakeholders consider field applications. However, given the wide array of variables that need to be considered, this modeling effort will be challenging and is likely to have a high degree of uncertainty.

\subsubsection{Relative Humidity}

Figure 8 indicates a negative correlation between relative humidity and NO oxidation rate for the mortar slabs (created with cement that contains $\mathrm{TiO}_{2}$ ) used in this study $\left(R^{2}=0.996, t=-22.257, d f=3, p\right.$ $=0.002)$. This correlation was also found in the study by Murata et al. $(2000)(t=-4.307, d f=5, p=0.013)$ and Hüsken and Brouwers (2008) and Hüsken et al. (2009) ( $t=-22.408, d f=7, p=0.000)$. Photocatalytic 
391 degradation of $\mathrm{NO}$ by pavement containing titanium dioxide occurs when $\mathrm{NO}$ is oxidized by ${ }^{\bullet} \mathrm{OH}$ (Figure

392 1). These ${ }^{\bullet} \mathrm{OH}$ are generated by oxidation of an $\mathrm{OH}^{-}$by an electron hole. Current understanding proposes

393 that water adsorbed on the slab serves as the source for $\mathrm{OH}^{-}$. Intuition would thereby suggest that

394 increased humidity would result in an increased rate of NO oxidation. By observation, the opposite has

395 been found to be true. In addition to photocatalytic properties, materials containing $\mathrm{TiO}_{2}$ also exhibit

396 photo-induced superhydrophilicity (i.e., water on the surface has a contact angle of nearly $0^{\circ}$ ) (Fujishima

397 et al., 2008). Adsorbed water vapor disperses over the surface, blinding photocatalytically active sites

398 (Beeldens, 2007).

399

400

401

402

403

404

405

406

407

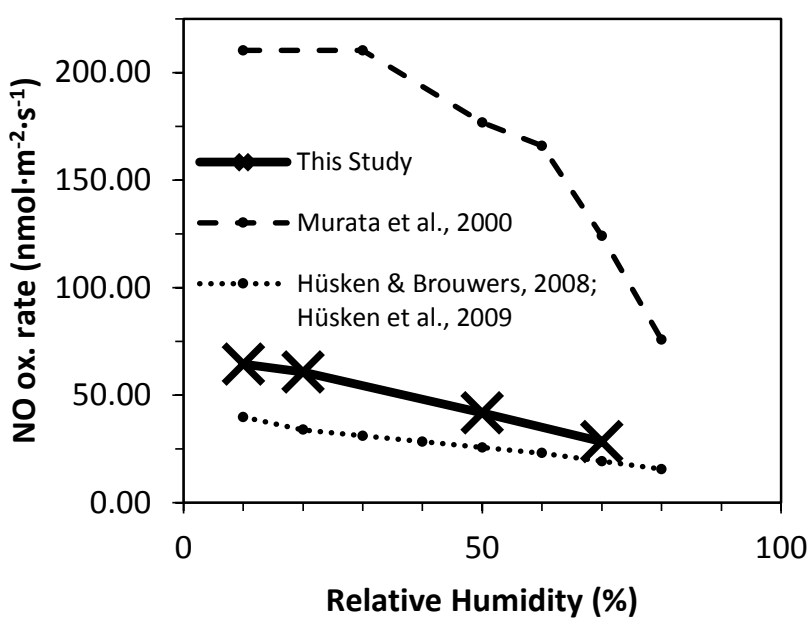

Figure 8. Effect of relative humidity on NO oxidation rate.

Although a negative correlation was found in each data set displayed in Figure 8, both data values and relationships differed. A null hypothesis that the difference in slopes of regression lines was 0 (i.e., $H_{0}: B_{1}$ $-B_{2}=0$ ) was used to compare this study's data to the data obtained by other researchers. This evaluation found a significant difference in slope between this study and both Murata et al. (2000) $(t=2.859, d f=6$, $p=0.029)$ and Hüsken and Brouwers (2008) and Hüsken et al. (2009) $(t=-9.378, d f=8, p=0.000)$. Evaluation of the $y$-intercept found a significant difference between this study and both Murata et al. (2000) $(t=-423.737, d f=6, p=0.000)$ and Hüsken and Brouwers (2008) and Hüsken et al. (2009) $(t=$ 
$978.105, d f=8, p=0.000$ ). This evaluation provides further evidence of the complexity of photocatalytic pavement materials. As concluded in previous sections, the researchers recommend that individual materials undergo a thorough evaluation prior to field evaluation.

The observed negative correlation that occurs as a result of water's blinding effect could limit the effectiveness of photocatalytic pavement in humid regions. Based on 2006-2008 data, the five counties with the highest ambient $\mathrm{NO}_{2}$ concentration in the form of the 2010-promulgated $\mathrm{NO}_{2}$ standard for counties within the United States are as follows: Cook, IL, San Diego, CA, Los Angeles, CA, Erie, NY, and Denver, CO (USEPA, 2010a). With the exception of Denver County, each of the listed counties frequently experiences high humidity conditions. As displayed in Figure 8, the NO oxidation rate at high humidity is substantially diminished. Unless photocatalytic pavements can be modified to lessen their sensitivity to changes in relative humidity, effective application in these polluted areas will be difficult.

\subsubsection{Decrease in Slab Moisture}

Figure 9 presents data obtained from a slab that was periodically removed from a $60^{\circ} \mathrm{C}$ oven and evaluated in the photoreactor as internal moisture decreased from a saturated state. For a decrease in moisture of $0-2 \%$ of saturated mass, a positive correlation is apparent $\left(R^{2}=0.822\right)$ and a 0 slope null hypothesis was rejected $(t=4.310, d f=5, p=0.013)$. Conversely, for a decrease in slab moisture greater than $2 \%$ of saturated mass, a negative correlation is apparent $\left(R^{2}=0.985\right)$ and a 0 slope null hypothesis was rejected ( $t=-14.152, d f=5, p=0.001)$. These observations can be explained as follows: between 0 and $2 \%$ decrease in moisture, as water is evaporated from the slab it no longer blinds active sites and the NO oxidation rate increases. This explanation is similar to the explanation for the correlation between relative humidity and NO oxidation rates. For a decrease in moisture above $2 \%$ the rate of NO oxidation appears to be limited because water contained within the slab is not available as a source for ${ }^{\bullet} \mathrm{OH}$. While the primary purpose of these results is to indicate that slab moisture influences NO oxidation rate, it is 
431 worth noting that these tests occurred at an average slab temperature of approximately $50^{\circ} \mathrm{C}$. Data

432 presented in Section 3.1.6 indicates that this elevated slab temperature increased reactivity by $60 \%$ in 433 comparison to slabs at $22^{\circ} \mathrm{C}$.

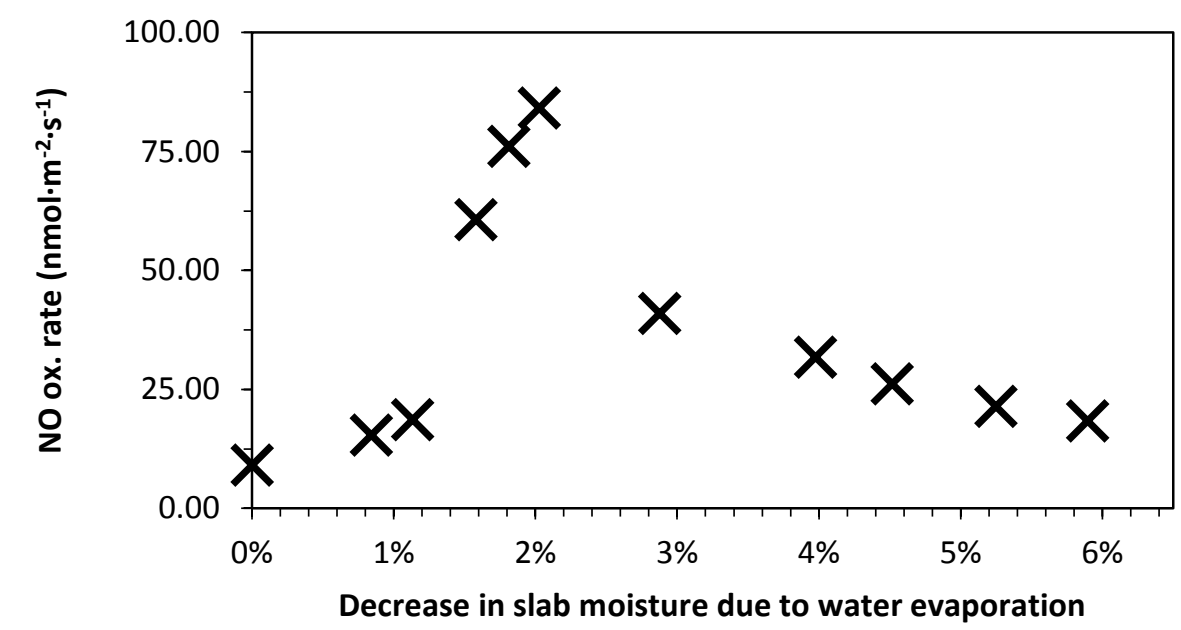

434

435

436

437

438

439

440

441

442

443

444 humidity remained low. However, sustained low humidity would also cause evaporation of water 445 contained in the pores of the slab. Based on the data presented, a photocatalytic concrete pavement 446 could be expected to remove NO initially; however, over time NO oxidation would decrease and the 447 benefits would be lost. If $\mathrm{TiO}_{2}$-containing pavement is to be applied in the field to mitigate NO pollution,

\section{Figure 9. Effect of decrease in slab moisture due to water evaporation on NO oxidation rate (photoreactor vapor density held constant).}

In this study, the peak NO oxidation rate was observed at $2 \%$ decrease in slab moisture. Under field condition a different peak would be observed. This difference would arise because water content varies throughout the depth of a concrete pavement; therefore, the decrease in moisture at the pavement surface would differ from the decrease in moisture throughout the entire slab. Overall, the findings presented in Figure 9 complicate recommendations for field application of $\mathrm{TiO}_{2}$-containing pavements.

On the basis of relative humidity, areas with sustained periods of low humidity would be recommended for application. It would be assumed that mitigation of NO pollution would continue as long as relative 

significant.

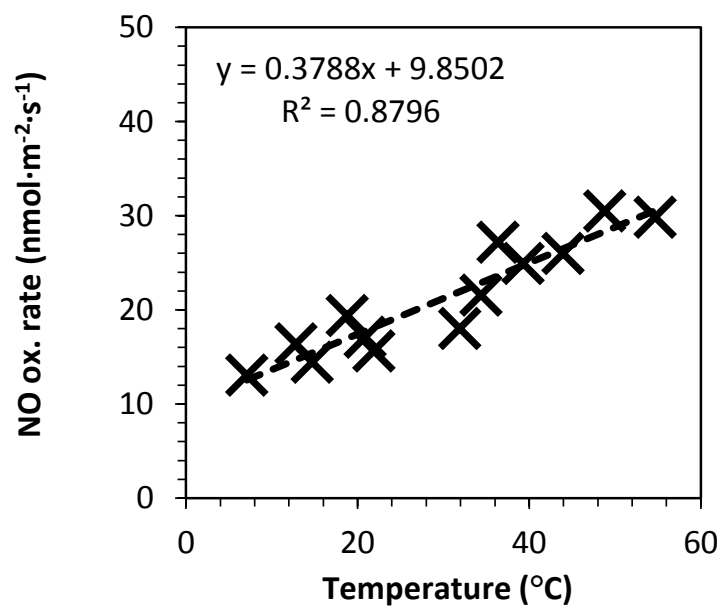

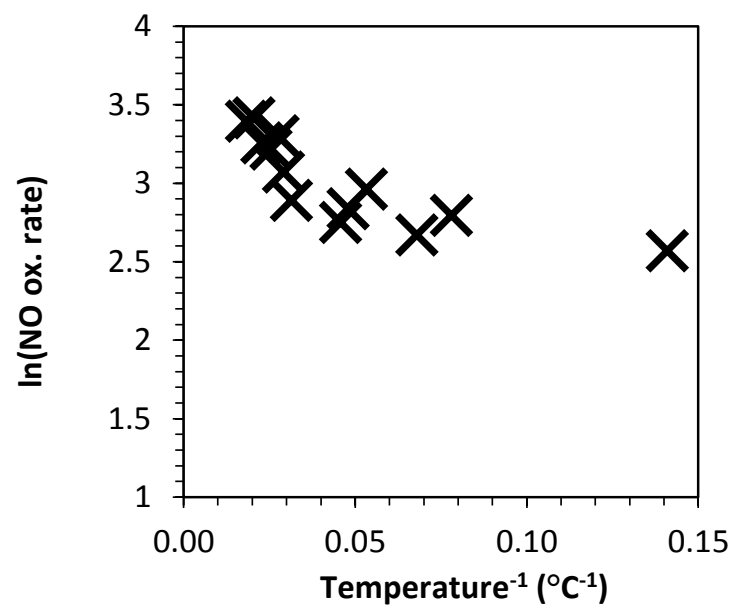

b. 
Figure 10. Effect of temperature on NO oxidation rate.

The effect of temperature on NO oxidation rates has not been studied in previous photoreactor studies; therefore, comparison with other data sets was not possible. Other photocatayltic pavement

467 studies that do make statements in regard to the impact of temperature on oxidation rates are often

468 vague. In most instances these studies assert that the oxidation rate increases with an increase in 469 temperature (Beeldens et al., 2011) and that only large differences in temperature (i.e., summer vs. 470 winter) are significant (Dylla et al., 2011). In addition to being vague, the literature also is contradictory 471 and one source reported a decrease in oxidation rate with increased temperature (Chen \& Chu, 2011).

472 One aqueous photocatalysis publication, Herrmann (1999), does provide useful insight for this study. It

473 stated that in the range of $20-80^{\circ} \mathrm{C}$, activation energy was negligible and was not a rate limiting step.

474 Furthermore, at temperatures below $0^{\circ} \mathrm{C}$, the apparent activation energy of the photocatalyst increased

475 leading to a decrease in oxidation rate.

476 The Arrhenius equation offers an empirical relationship between a reaction rate constant $(k)$, 477 temperature $(T)$, pre-exponential factor $(A)$, activation energy $\left(E_{a}\right)$, and the universal gas constant $(R)$ :

$$
k=A \cdot e^{\frac{-E_{a}}{R \cdot T}}
$$

479 Using log properties, this equation can also be expressed as follows:

480

$$
\ln k=\frac{-E_{a}}{R}\left(\frac{1}{T}\right)+\ln A
$$

481 When graphed on axes of $\ln (\mathrm{NO}$ oxidation rate) and the inverse of temperature $(1 / T)$, reactions that 482 follow the Arrhenius equation exhibit a linear relationship. Figure 10b does not display this type of 483 relationship. Overall, while the information discussed in this section partially explains the observations; it 484 would appear that given the complexity of photocatalytic pavement materials, other factors also 485 influenced the reported observations. 
Photocatalytic pavements offer a novel technological option to mitigate $\mathrm{NO}_{x}$ pollution. In order for these pavements to be adopted by potential stakeholders, information is needed that documents the NO oxidation rate under varied environmental conditions. A positive correlation was observed between NO oxidation rate and influent NO concentration. Comparison of this study with Hüsken and Brouwers (2008), Hüsken et al. (2009) and Ballari et al. (2010), who also studied cementitious photocatalytic pavements,

492 found no significant difference in the slope of regression lines through this data. However, a significant 493 difference in slope was observed in comparison with Murata et al. (2000). A positive correlation was also 494 observed between NO oxidation rates and UV-A irradiance $\left(R^{2}=0.996\right)$. Comparison of this study with 495 Hüsken et al. (2009) found no significant difference in the slope of regression lines through this data. A 496 significant difference in slope was observed in comparison with Murata et al. (2000). A correlation was 497 not observed between NO oxidation rates and flow rate. This same conclusion was reached with analysis 498 of data from Hüsken and Brouwers (2008) and Hüsken et al. (2009). A negative correlation was observed between NO oxidation rate and relative humidity. In contrast with evaluations for UV-A irradiance and NO 500 concentration, no significant difference was found with comparison of this study to Murata et al. (2000). 501 A significant difference in slope was observed between this study and Hüsken and Brouwers (2008) and 502 Hüsken et al. (2009). Decrease in slab moisture, a variable not investigated in prior work, was found to 503 affect NO oxidation rates. At losses of $0-2 \%$ of saturated mass, a positive correlation was observed; 504 whereas, at losses greater that $2 \%$ a negative correlation was observed. A positive correlation was documented for slab temperature. This finding contrasts previous assertions which considered this variable insignificant.

Overall, it can be concluded that photocatalytic mortar slabs manufactured with TX Active pavement 508 are highly sensitive to changes in environmental variables. NO oxidation rates observed in this study ranged from $9.8-64 \mathrm{nmol} \cdot \mathrm{m}^{-2} \cdot \mathrm{s}^{-1}$. Furthermore, significant differences were found by comparison to other 
510

511

512

513

514

515

516

517

studies. Therefore, if a potential stakeholder is considering use of this technology to mitigate $\mathrm{NO}_{\mathrm{x}}$ emissions, careful preliminary work should be undertaken to both evaluate the environmental conditions of the test site and the properties of the selected photocatalytic material.

\section{Acknowledgments}

The authors wish to thank the National Concrete Pavement Technology Center, the United States

Department of Transportation (grant number removed to ensure blind review), Essroc Italcementi Group, and Lehigh Hanson, Inc. for providing funding to pursue this study. The authors also thank H. Bai and L. Y.

Ong for their role in data collection and analysis.

\section{References}

Ballari, M. M., Hunger, M., Hüsken, G., \& Brouwers, H. J. H. (2010). NOx photocatalytic degradation employing concrete pavement containing titanium dioxide. Applied Catalysis B-Environmental, 95(3-4), 245-254. doi: 10.1016/j.apcatb.2010.01.002

Ballari, M. M., Yu, Q. L., \& Brouwers, H. J. H. (2011). Experimental study of the NO and NO2 degradation by photocatalytically active concrete. Catalysis Today, 161(1), 175-180. doi: 10.1016/j.cattod.2010.09.028

Beeldens, A. (2007, October 8-9). Air Purification by Road Materials: Results of the Test Project in Antwerp. Paper presented at the International RILEM Symposium on Photocatalysis, Environment and Construction Materials - TDP 2007, Florence, Italy.

Beeldens, A., Cassar, L., \& Murata, Y. (2011). Applications of TiO2 Photocatalysis for Air Purification In Y. Ohama \& D. Van Gemert (Eds.), Application of titanium Dioxide Photocatalysis to Construction Materials (1st ed.): Springer.

Bigi, A., \& Harrison, R. M. (2010). Analysis of the air pollution climate at a central urban background site. Atmospheric Environment, 44(16), 2004-2012. doi: 10.1016/j.atmosenv.2010.02.028

Brauer, M., Hoek, G., Van Vliet, P., Meliefste, K., Fischer, P. H., Wijga, A., . . Brunekreef, B. (2002). Air pollution from traffic and the development of respiratory infections and asthmatic and allergic symptoms in children. American Journal of Respiratory and Critical Care Medicine, 166(8), 10921098. doi: DOI 10.1164/rccm.200108-0070C 
Brunekreef, B., Janssen, N. A. H., deHartog, J., Harssema, H., Knape, M., \& vanVliet, P. (1997). Air pollution from truck traffic and lung function in children living near motorways. Epidemiology, 8(3), 298303.

Chen, M., \& Chu, J. W. (2011). NO(x) photocatalytic degradation on active concrete road surface - from experiment to real-scale application. [Article]. Journal of Cleaner Production, 19(11), 1266-1272. doi: 10.1016/j.jclepro.2011.03.001

Clean Air Act, 42 U.S.C. § 7401 et seq. (2008).

Dylla, H., Hassan, M. M., Mohammad, L. N., Rupnow, T., \& Wright, E. (2010). Evaluation of Environmental Effectiveness of Titanium Dioxide Photocatalyst Coating for Concrete Pavement. Transportation Research Record: Journal of the Transportation Research Board, 2164(-1), 46-51. doi: 10.3141/2164-06

Dylla, H., Hassan, M. M., Schmitt, M., Rupnow, T., \& Mohammad, L. N. (2011). Laboratory Investigation of the Effect of Mixed Nitrogen Dioxide and Nitrogen Oxide Gases on Titanium Dioxide Photocatalytic Efficiency in Concrete Pavements. Journal of Materials in Civil Engineering, 23(7), 1087-1093. doi: 10.1061/(asce)mt.1943-5533.0000248

Finkelstein, M. M., Jerrett, M., \& Sears, M. R. (2004). Traffic air pollution and mortality rate advancement periods. American Journal of Epidemiology, 160(2), 173-177. doi: Doi 10.1093/Aje/Kwh181

Fujishima, A., Zhang, X. T., \& Tryk, D. A. (2008). TiO(2) photocatalysis and related surface phenomena. [Review]. Surface Science Reports, 63(12), 515-582. doi: 10.1016/j.surfrep.2008.10.001

Garshick, E., Laden, F., Hart, J. E., \& Caron, A. (2003). Residence near a major road and respiratory symptoms in US veterans. Epidemiology, 14(6), 728-736. doi: DOI 10.1097/01.ede.0000082045.50073.66

Grant, R. H., \& Slusser, J. R. (2005). Estimation of ultraviolet-A irradiance from measurements of 368-nm spectral irradiance. Journal of Atmospheric and Oceanic Technology, 22(12), 1853-1863. doi: 10.1175/jtech1823.1

Herrmann, J. M. (1999). Heterogeneous photocatalysis: fundamentals and applications to the removal of various types of aqueous pollutants. Catalysis Today, 53(1), 115-129.

Herrmann, J. M., Péruchon, L., Puzenat, E., \& Guillard, C. (2007, October 8-9). Photocatalysis: from fundamentals to self-cleaning glass applications. Paper presented at the International RILEM Symposium on Photocatalysis, Environment and Construction Materials - TDP 2007, Florence, Italy.

Herrmann, J. M. (2010). Photocatalysis fundamentals revisited to avoid several misconceptions. Applied Catalysis B: Environmental, 99(3), 461-468. 
Hunger, M., Hüsken, G., \& Brouwers, H. (2010). Photocatalytic degradation of air pollutants-From modeling to large scale application. Cement and Concrete Research, 40(2), 313-320.

Hüsken, G., \& Brouwers, H. J. H. (2008, June 16-20). Air purification by cementitious materials: Evaluation of air purifying properties. Paper presented at the International Conference on Construction and Building Technology, Kuala Lumpur, Malaysia.

Hüsken, G., Hunger, M., \& Brouwers, H. J. H. (2009). Experimental study of photocatalytic concrete products for air purification. Building and Environment, 44(12), 2463-2474. doi: DOI 10.1016/j.buildenv.2009.04.010

ISO. (2007). Fine ceramics (advanced ceramics, advanced technical ceramics) -- Test method for airpurification performance of semiconducting photocatalytic materials -- Part 1: Removal of nitric oxide (Vol. 22197-1:2007): ISO.

Jacoby, W. A., Blake, D. M., Noble, R. D., \& Koval, C. A. (1995). KINETICS OF THE OXIDATION OF TRICHLOROETHYLENE IN AIR VIA HETEROGENEOUS PHOTOCATALYSIS. Journal of Catalysis, 157(1), 87-96. doi: 10.1006/jcat.1995.1270

Kim, J. J., Smorodinsky, S., Lipsett, M., Singer, B. C., Hodgson, A. T., \& Ostro, B. (2004). Traffic-related air pollution near busy roads - The East Bay children's respiratory health study. American Journal of Respiratory and Critical Care Medicine, 170(5), 520-526. doi: DOI 10.1164/rccm.200403-2810C

Kumar, P., Dushenkov, V., Motto, H., \& Raskin, I. (1995). PHYTOEXTRACTION - THE USE OF PLANTS TO REMOVE HEAVY-METALS FROM SOILS. Environmental Science \& Technology, 29(5), 1232-1238. doi: 10.1021/es00005a014

Kundu, P. K., \& Cohen, I. M. (2010). Fluid Mechanics: Elsevier Science.

Lim, T. H., Jeong, S. M., Kim, S. D., \& Gyenis, J. (2000). Photocatalytic decomposition of NO by TiO2 particles. Journal of Photochemistry and Photobiology a-Chemistry, 134(3), 209-217. doi: 10.1016/s1010-6030(00)00265-3

Long, C. S., Miller, A. J., Lee, H. T., Wild, J. D., Przywarty, R. C., \& Hufford, D. (1996). Ultraviolet Index Forecasts Issued by the National Weather Service. Bulletin of the American Meteorological Society, 77(4), 729-748.

Minero, C., Bedini, A., \& Minella, M. (2013). On the standardization of the photocatalytic gas/solid tests. International Journal of Chemical Reactor Engineering, 11(2), 717-732.

Murata, Y., Kamitani, K., \& Takeuchi, K. (2000). Air Purifying Blocks Based on Photocatalysis. Paper presented at the Japan Interlocking BLock Pavement Engineering Association World Congress 2000, Tokyo, Japan. 
602

603

604

605

606

607

608

609

610

611

612

613

614

615

616

617

618

619

620

621

622

623

624

625

626

627

628

629

630

631

632

633

634

Murata, Y., \& Tobinai, K. (2002). Influence of various factors on NOx removal performance of permeable interlocking block based on photocatalysis. Journal of Structural and Construction Engineering(Transactions of AIJ)(555), 9-15.

Obee, T. N., \& Brown, R. T. (1995). TIO2 PHOTOCATALYSIS FOR INDOOR AIR APPLICATIONS - EFFECTS OF HUMIDITY AND TRACE CONTAMINANT LEVELS ON THE OXIDATION RATES OF FORMALDEHYDE, TOLUENE, AND 1,3-BUTADIENE. Environmental Science \& Technology, 29(5), 1223-1231. doi: 10.1021/es00005a013

Paz, Y. (2010). Application of TiO2 photocatalysis for air treatment: Patents' overview. Applied Catalysis B-Environmental, 99(3-4), 448-460. doi: 10.1016/j.apcatb.2010.05.011

Primary National Ambient Air Quality Standards for Nitrogen Dioxide: Final Rule, 75 Fed. Reg. 6474 (2010) (to be codified at 40 C.F.R. pts. 50 and 58).

Primary National Ambient Air Quality Standards for Nitrogen Dioxide: Proposed Rule, 75 Fed. Reg. 34404 (2009) (to be codified at 40 C.F.R. pts. 50 and 58).

Thoma, E. D., Shores, R. C., Isakov, V., \& Baldauf, R. W. (2008). Characterization of near-road pollutant gradients using path-integrated optical remote sensing. Journal of the Air \& Waste Management Association, 58(7), 879-890. doi: Doi 10.3155/1047-3289.58.7.879

USEPA. (2001). National Air Quality and Emissions Trends Report, 1999. (EPA 454/R-01-004). Washington, D.C.

USEPA. (2007). Summary of Current and Historical Light-Duty Vehicle Emission Standards. Washington, D.C.: Retrieved from http://www.epa.gov/greenvehicles/detailedchart.pdf.

USEPA. (2008a). Average Annual Emissions and Fuel Consumption for Gasoline-Fueled Passenger Cars and Light Trucks. (EPA420-F-08-024). Washington, D.C.: Retrieved from http://www.epa.gov/otaq/consumer/420f08024.pdf.

USEPA. (2008b). Integrated Science Assessment for Oxides of Nitrogen - Health Criteria (Final Report). (EPA/600/R-08/071, 2008). Washington, D.C.

USEPA. (2010a). Design Values (Average 1-Hour 98th Percentiles over 3 Years) by County for Nitrogen Dioxide Research Triangle Park, NC: Retrieved from http://www.epa.gov/oaqps001/nitrogenoxides/pdfs/NO2 final designvalues 0608 Jan22.pdf.

USEPA. (2010b). Final Regulatory Impact Analysis (RIA) for the $\mathrm{NO}_{2}$ National Ambient Air QUality Standards (NAAQS). Research Triangle Park, NC: Retrieved from http://www.epa.gov/ttnecas1/regdata/RIAs/FinalNO2RIAfulldocument.pdf.

USEPA. (2011, July 6). Nitrogen Dioxide: Health Retrieved September 27, 2011, from http://www.epa.gov/air/nitrogenoxides/health.html 


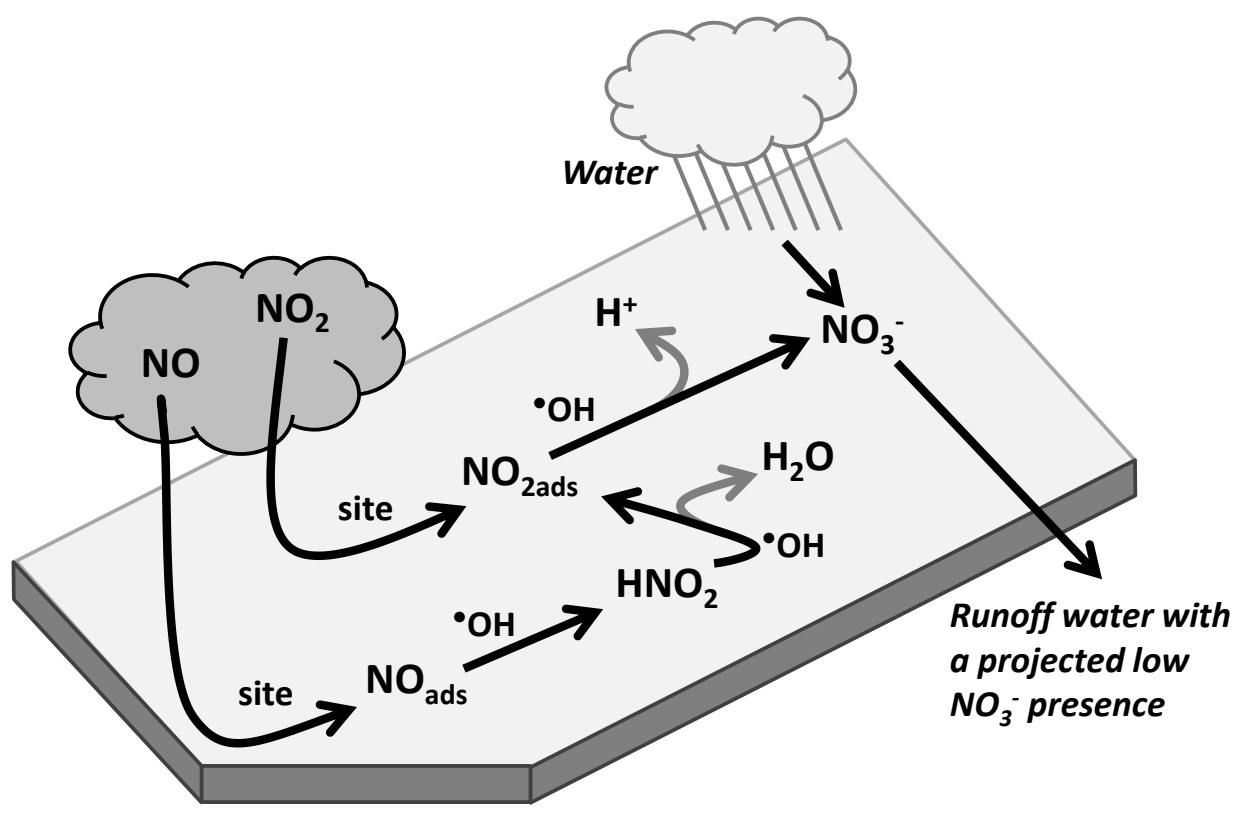

Figure1. Photocatalytic oxidation of $\mathrm{NO}$ and $\mathrm{NO}_{2}$ by pavement containing $\mathrm{TiO}_{2}$ (partially adapted from

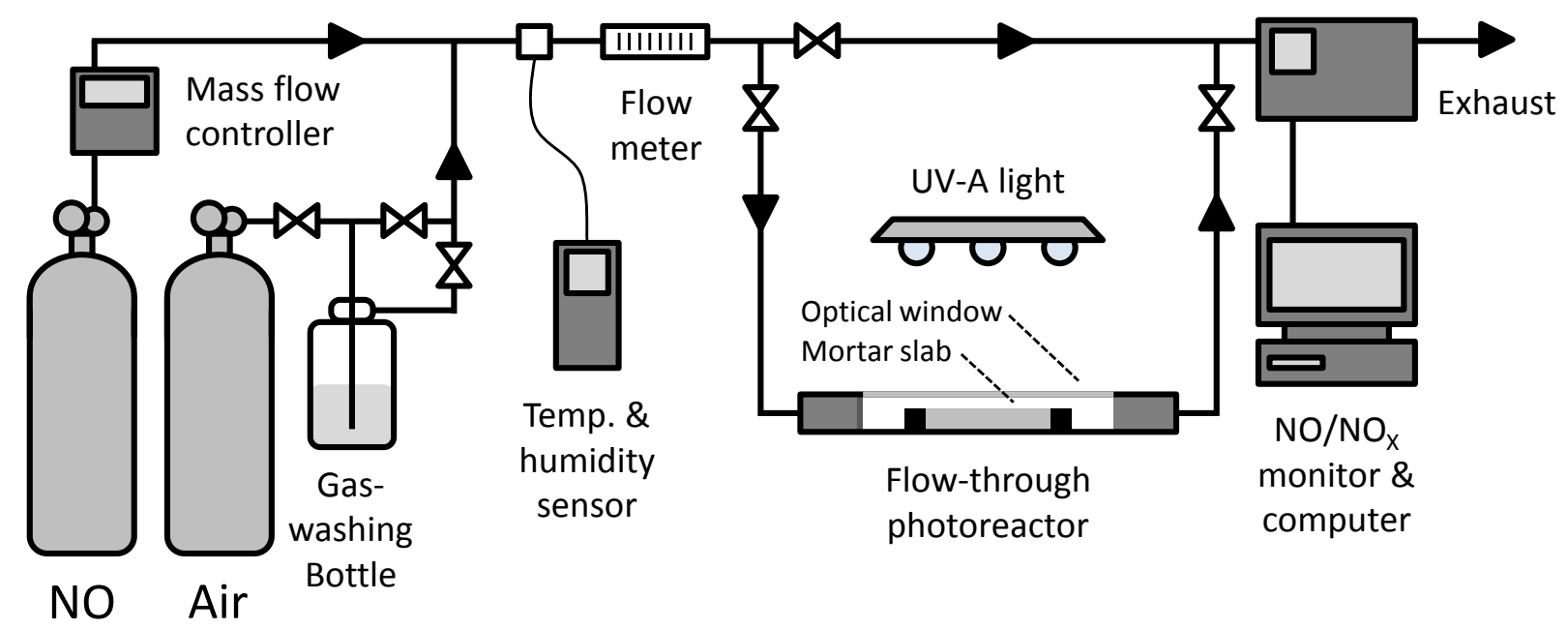

Figure 2. Diagram of experimental apparatus (partially adapted from Ballari et al., 2011). 


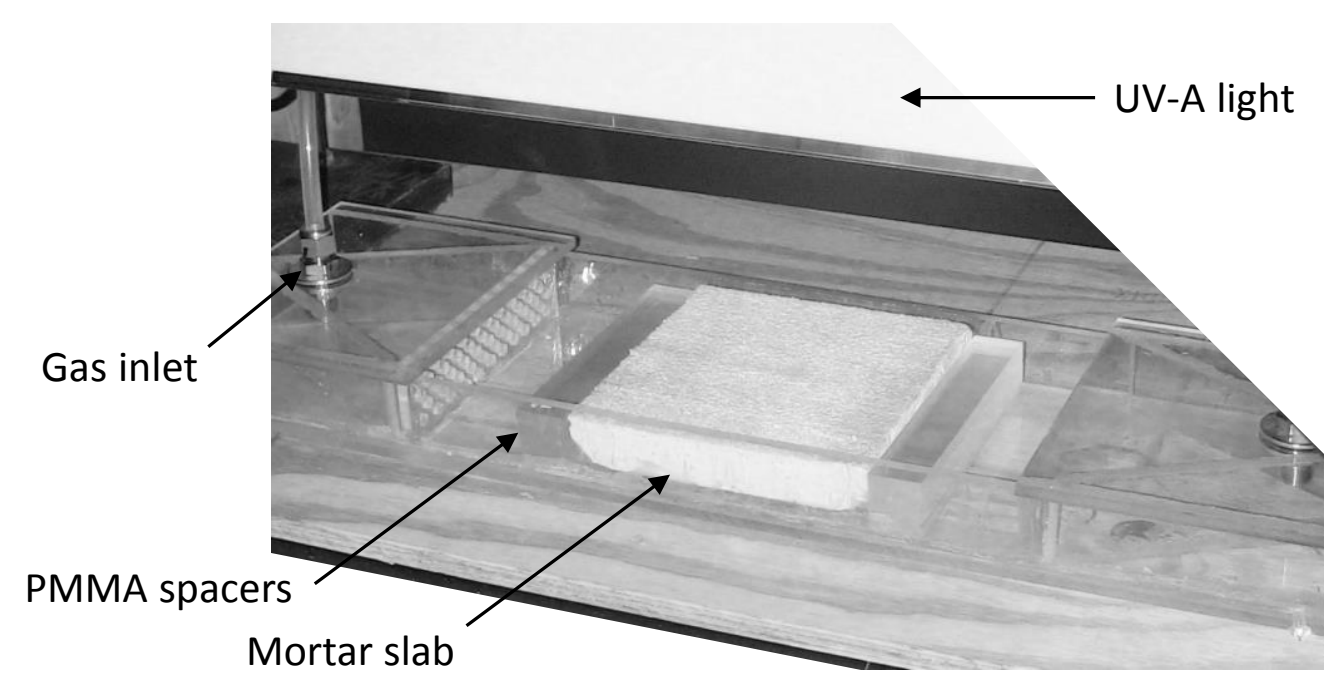

644 Figure 3. Photograph of photoreactor and mortar slab (optical window removed to facilitate viewing). 